Open Access Full Text Article

ORIGINAL RESEARCH

\title{
Serum Cleaved Tau Protein and Clinical Outcome in Patients with Minor Head Trauma
}

This article was published in the following Dove Press journal:

Open Access Emergency Medicine

\author{
Arash Forouzan (1D) \\ Hassan Motamed (1D' \\ Ali Delirrooyfard' \\ Sara Zallaghi ${ }^{2}$ \\ 'Department of Emergency Medicine, \\ Ahvaz Jundishapur University of Medical \\ Sciences, Ahvaz, Iran; ${ }^{2}$ Ahvaz Jundishapur \\ University of Medical Sciences, Ahvaz, Iran
}

Correspondence: Ali Delirrooyfard Department of Emergency Medicine, Ahvaz Jundishapur University of Medical

Sciences, Ahvaz, Iran

Tel/Fax +986132229166

Email adelir289I@gmail.com
Introduction: Minor head trauma is due to the transfer of a mechanical energy to the brain caused by a traumatic event. The present study was accomplished aiming to investigate the cleaved tau protein (CTP) as a brain injury biomarker among patients with minor head trauma. Patients and Methods: This observational study was performed on patients with minor head trauma in 2017 who referred to emergency department of Imam Khomeini Hospital and Golestan Hospital of Ahvaz, Iran. The patients over the age of 16 years old with minor head trauma, who had computed tomography (CT) scan at most $10 \mathrm{hrs}$ after the incident, and consented to participate in the study, were enrolled. C-tau evaluation was performed by the enzyme-linked immunosorbent assay (ELISA) method with monoclonal antibodies detecting the C-tau marker. Investigation of the injury after 3 months of minor head trauma was conducted using a post-concussion syndrome questionnaire (RPCS).

Results: In this study, 86 patients were evaluated. CTP was positive in $14 \%$ of the patients and the results revealed that there was a significant relationship between traumatic brain injury (TBI) and positive CTP $(\mathrm{p}<0.0001)$. The CTP had a sensitivity and specificity of, respectively, $92 \%$ and $100 \%$ in detecting intracranial trauma. In addition, positive and negative predictive powers for this marker were $100 \%$ and $98 \%$, respectively.

Conclusion: In general, contrary to previous studies, the findings of this study suggest that evaluation of the CTP levels can be a strong biomarker with high sensitivity and specificity in detecting TBI.

Keywords: craniocerebral trauma, head trauma, biomarker, tau proteins, computed tomography

\section{Introduction}

The minor head trauma is caused by the transfer of mechanical energy to the brain because of a traumatic event, such as rapid change in motion, a direct effect on the head, or an explosion. ${ }^{1,5}$ In recent years, the number of people suffering from minor head trauma has had an increasing trend. ${ }^{2,3}$

Minor head trauma is accompanied by several neurological, cognitive, and behavioral symptoms, and may result in increased intracranial pressure (IICP) and post-concussion syndrome (PCS) in long run. ${ }^{4,5}$

Traumatic brain injury (TBI) is one of the causes of mortality and disability among individuals, and in numerous studies, TBI has been shown to be one of the risk factors for Alzheimer's disease (AD). ${ }^{6-8}$ Annually, 10 million people experience TBI worldwide, and minor head traumas account for $70-90 \%$ of these cases. The incidence of mild traumatic brain injury (mTBI) in the United States has been estimated to be more than 1.6 million annually. ${ }^{9}$ However, the pathophysiology of 
mTBI has not been specified, and thus there has not been proper diagnosis, identification, and therapeutic strategies so far. Due to limitations in brain imaging techniques and incomplete diagnostic methods, researchers have embarked on examining mTBI at the cell and molecular level, and are attempting to identify the blood markers associated with brain damage. ${ }^{10}$

Currently, various types of TBI are diagnosed based on clinical evaluations and the Glasgow Coma Scale (GCS) rating system, along with neurological examinations and CT scan imaging, each with its own limitations in predicting major functional problems caused by TBI. ${ }^{11}$ GCS is effective in evaluating the patient's neurological status and has a wide clinical application; however, it may be affected by polytrauma, and factors such as drug and alcohol consumption by the patient and other extracranial injuries. Moreover, clinical CT imaging is not usually capable of detecting mild to moderate trauma, expose the patient to ionizing radiation, and is a relatively costly method. ${ }^{12}$

Neurofilament heavy chain protein (NF-H), glial fibrillary acidic protein (GFAP), ubiquitin C-terminal hydrolase-L1 (UCHL1), neuron-specific enolase (NSE), myelin basic protein (MBP), tau, and s $100 \beta$ blood biomarkers are elevated during the mTBI. The tau protein is a member of the family of microtubule-associated proteins (MAPs) that contributes to maintaining the cytoskeleton structure and axonal transmission. This protein is secreted by the central nervous system (CNS) neurons and oligodendrocytes, and is predominantly present in the axon of unmyelinated neurons and the cortex among neurons. ${ }^{13}$ This marker is utilized to diagnose $\mathrm{AD}$, as well as high tau levels in cerebrospinal fluid (CSF) and serum with CNS injuries, such as TBI and stroke. ${ }^{14,15}$

Bulut et al examined the serum levels of tau protein after minor head trauma; however, no significant difference was reported between the serum tau level among patients with mTBI and the control group. ${ }^{5}$ Serum cleaved-tau (C-tau) level may be a better marker for detecting minor head trauma in comparison to tau. Axon damage in the minor trauma results in proteolysis of the tau protein and, hence, production of the C-tau. ${ }^{16}$

Since the minor head trauma has a high incidence rate and its diagnosis still remains one of the clinical problems that may be accompanied by many complications for the patient, the identification of biomarkers for diagnosing this disorder and managing patients, especially those at risk is important. ${ }^{17}$ Therefore, the current study was conducted with the aim to evaluate the C-tau protein (CTP) as a brain injury biomarker among patients with minor head trauma.

\section{Patients and Methods Study Design and Setting}

This descriptive-observational epidemiological study was conducted on patients with minor head trauma in 2017 who referred to the emergency department of Imam Khomeini Hospital and Golestan Hospital of Ahvaz, Iran.

\section{Participants}

\section{Inclusion Criteria}

After receiving the Ethics Code (IR.AJUMS. REC.1396.186) from the Ahvaz Jundishapur University of Medical Sciences (AJUMS) Ethics Committee, that the patient consent was written with informed consent and carried out in accordance with the Helsinki Declaration. Patients over the age of 16 years old, with minor head trauma and a CT image of a maximum of $10 \mathrm{hrs}$ after the incident, as well as with consent to participate in the study, were enrolled in the study. The patients under the age of 18 years were able to consent on their own behalf or if a parent or legal guardian provided the consent. Patients with minor head trauma were categorized in terms of post-traumatic amnesia (PTA) for less than $24 \mathrm{hrs,} \mathrm{loss} \mathrm{of} \mathrm{consciousness} \mathrm{of}$ less than $30 \mathrm{mins}$, and GCS scale at the time of admission to the emergency department, which was between 13 and 15.5

\section{Exclusion Criteria}

Similarly, patients that more than $10 \mathrm{hrs}$ had passed from their injury, had systolic blood pressure less than 90 mmHg, oxygen saturation less than $92 \%$, known neurological or psychiatric disorders, spinal cord injury, posttraumatic focal neuropathy, and also patients requiring recovery, with a history of alcohol use, or drug addiction, or unwilling to participate in the study, were excluded.

\section{Data Measurement}

Initially, demographic information of the patients and details about the minor head trauma, including the cause of the injury, the time of the injury, the location of the injury and the severity of the injury, as well as the patient's condition at arrival (nausea, vomiting, dizziness, imbalance, impairment in memory and alertness, etc.) were recorded. The severity of the injury was measured by the GCS.

In this study, CT images were taken for all patients at the time of arrival (within $10 \mathrm{hrs}$ after the incident) and 
according to the results, the presence or lack of minor head trauma was examined and recorded. The head CT image was interpreted by a radiologist who was not aware of the patient's information. Any abnormalities identified in the brain CT were considered as a minor head trauma.

\section{C-Tau Evaluation}

In this study, blood sample was taken from all patients with minor head trauma in order for the evaluation of serum C-tau level. Then, the blood samples were poured into serum separator tubes (SSTs) and centrifuged for 15 mins at about $3000 \mathrm{rpm}$. Serum samples were stored in the freezer $\left(70^{\circ} \mathrm{C}\right)$ until they were used. $\mathrm{C}$-tau evaluation was performed by the enzyme-linked immunosorbent assay (ELISA) method with monoclonal antibodies detecting the C-tau marker. ${ }^{10}$

The lowest detection limit for the C-tau marker in the ELISA method was $5.1 \mathrm{ng} / \mathrm{mL}$, which was considered to be "zero" in all analyses, and the values more than this limit were considered as positive. Since the pharmacokinetic details of C-tau were unknown; thus, only the presence or absence of C-tau was checked and recorded in this study.

\section{PCS of Patients}

Investigation of the injury after 3 months of minor head trauma was carried out using the post-concussion syndrome questionnaire (RPCS). ${ }^{5}$ In the PCS 16 questionnaire, signs and symptoms of head trauma were examined using responses of 4 to 0 . After calculating the total score of the individual, a higher score indicated a worse condition of the individual. Finally, the frequency of PCS and its relationship with the tau-C marker were investigated.

\section{Statistical Methods}

The data were analyzed by descriptive statistics including mean, standard deviation (SD), percentage, tables, and figures, in addition, the inferential statistics including $t$-test for two independent groups. Moreover, the diagnostic value of this marker was also reported by sensitivity, specificity, and positive predictive value (PPV), negative predictive value (NPV), and receiver operating characteristic (ROC) charts.

\section{Results}

In this study, 86 patients were evaluated. The mean age of the patients was $31.4 \pm 13.9$ years. Furthermore, $70.9 \%$ of the patients were men. The mean time between incident and radiological evaluation was $2.9 \pm 1.6 \mathrm{hrs}$. The patients' GCS was $14.9 \pm 1.25$ hrs (Table 1).

The most prevalent post-traumatic complications in this study were loss of consciousness, observed in about one-third of the patients, followed by PTA, and nausea and vomiting. TBI was diagnosed in $12.8 \%$ of the patients. In addition, the CTP was positive among $14 \%$ of the patients (Table 1, Figure 1).

In terms of factors examined for positive and negative TBI cases, it was found that there was a significant relationship between intracranial injury and positive CTP (Table 2).

The tau protein has a sensitivity and specificity of $92 \%$ and $100 \%$, respectively, in detecting TBI. Moreover, the positive and negative predictive powers for this marker were, respectively, $100 \%$ and $98 \%$ (Table 3).

Since the prevalence rate of rhinorrhea complications and loss of consciousness in patients with intracranial injury was higher, this symptom was evaluated separately in relation with the intracranial injury. Based on these findings, it was revealed that there was no significant relationship between symptoms and the incidence of intracranial injury (Table 4).

The sensitivity, specificity, and risk level of these two clinical symptoms were evaluated in the evaluation of intracranial injury. The findings indicated that rhinorrhea had sensitivity and specificity of $16 \%$ and $97 \%$, respectively.

Table I Baseline Characteristics

\begin{tabular}{|l|l|l|}
\hline \multicolumn{2}{|l|}{ Variables } & Results \\
\hline Age, Mean \pm SD (range) & $31.4 \pm 13.94$ (I6-90) \\
\hline Gender, N (\%) & $61(70.9)$ \\
\hline \multicolumn{2}{|l|}{ Time to admission, Mean \pm SD (range) } & $2.9 \pm 1.6(1-8)$ \\
\hline GCS, $n$ (\%) & 13 & $7(8.2)$ \\
& 14 & $18(20.9)$ \\
& 15 & $61(70.9)$ \\
\hline Complications, $n$ (\%) & PTA & $16(18.6)$ \\
& LOC & $26(30.2)$ \\
& Dizziness & $3(3.5)$ \\
& Nausea and vomiting & $19(22.1)$ \\
& Rinorragia & $4(4.7)$ \\
& Confusion & $2(2.3)$ \\
& Headache & $13(15.1)$ \\
\hline Brain injury, $n$ (\%) & Positive & $11(12.8)$ \\
& Negative & $75(87.2)$ \\
\hline Tau protein, n (\%) & Yes & $12(14)$ \\
& No & $74(86)$ \\
\hline
\end{tabular}




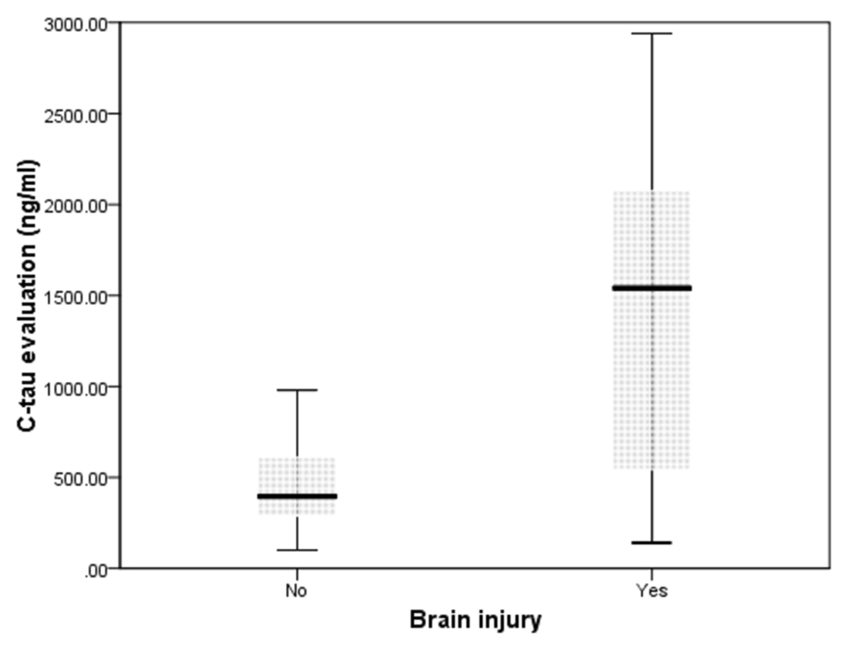

Figure I Serum cleaved tau protein in two groups of brain injury.

Furthermore, sensitivity and specificity of loss of consciousness were, respectively, $50 \%$ and $72 \%$.

\section{Discussion}

So far, a lot of biomarkers have been introduced in relation with the CNS injuries, including neuron-specific enolase, glycoproteins, glial fibrillary acidic protein (GFAP), myelin basic protein (MBP), and cleaved tau protein (CTP). Tau protein is a microtubule-linked phosphoprotein seen in normal neural axons. In addition, its mutated type has been observed in neurodegenerative diseases. ${ }^{18}$ In fact, the tau protein changes as proteolytic after exposure to axonal damage and converts to CTP. Therefore, the CTP level

Table 2 Factors Examined for TBI Cases

\begin{tabular}{|c|c|c|c|c|}
\hline \multicolumn{2}{|l|}{ Variables } & \multicolumn{2}{|c|}{ Brain Injury } & \multirow[t]{2}{*}{ P-value } \\
\hline & & $\begin{array}{l}\text { Yes } \\
(n=I I)\end{array}$ & $\begin{array}{l}\text { No } \\
(n=74)\end{array}$ & \\
\hline Gender & $\begin{array}{l}\text { Male } \\
\text { Female }\end{array}$ & $\begin{array}{l}7(66.7 \%) \\
4(33.3 \%)\end{array}$ & $\begin{array}{l}53(71.6 \%) \\
21(28.4 \%)\end{array}$ & 0.48 \\
\hline Complications & $\begin{array}{l}\text { PTA } \\
\text { LOC } \\
\text { Dizziness } \\
\text { PTA } \\
\text { Nausea and } \\
\text { vomiting } \\
\text { Rinorragia } \\
\text { Confusion } \\
\text { Headache }\end{array}$ & $\begin{array}{l}I(8.3 \%) \\
6(50 \%) \\
0 \\
0 \\
I(8.3 \%) \\
2(16.6 \%) \\
I(8.3 \%) \\
I(8.3 \%)\end{array}$ & $\begin{array}{l}15(20.3 \%) \\
20(27 \%) \\
3(4.1 \%) \\
3(4.1 \%) \\
18(24.3 \%) \\
2(2.7 \%) \\
1(1.4 \%) \\
12(16.2 \%)\end{array}$ & 0.11 \\
\hline Tau protein & $\begin{array}{l}\text { Positive } \\
\text { Negative }\end{array}$ & $\begin{array}{l}\mathrm{II}(100 \%) \\
0\end{array}$ & $\begin{array}{l}I(1.2 \%) \\
74(98.8 \%)\end{array}$ & $<0.0001$ \\
\hline
\end{tabular}

Table 3 Diagnostic Accuracy of the Cleaved Tau Protein Marker in Detecting Traumatic Brain Injury

\begin{tabular}{|l|l|l|l|}
\hline Diagnostic Accuracy & Percent & \multicolumn{2}{|l|}{$\begin{array}{l}\text { 95\% Confidence } \\
\text { Interval }\end{array}$} \\
\cline { 3 - 4 } & & Upper & Lower \\
\cline { 3 - 4 } & & 0.61 & 99.70 \\
Sensitivity & 0.92 & 0.95 & 1.00 \\
Specificity & 1.00 & 0.71 & 1.00 \\
Positive Predictive Value (PPV) & 1.00 & 0.92 & 0.99 \\
Negative Predictive Value (NPV) & 0.98 & & \\
\hline
\end{tabular}

Table 4 Post-Concussion Syndrome Questionnaire (RPCS) After Three Months of Minor Head Trauma

\begin{tabular}{|l|l|l|}
\hline Post-Concussion Syndrome & N & $\begin{array}{l}\text { Percent } \\
\text { Questionnaire }\end{array}$ \\
\hline Headache \& PTA & 10 & 44.00 \\
Decreased LOC & I7 & 41.12 \\
Headache \& Vertigo & 4 & 32.00 \\
Headache \& Vomiting & I & 43.00 \\
Decreased LOC \& Confusion & 2 & 45.00 \\
Rhinorragia \& Nausea & I & 27.00 \\
Headache \& Nausea & I3 & 44.65 \\
Rhinorragia & I & 33.00 \\
Nausea \& Vomiting & II & 40.55 \\
Nausea \& Vomiting \& PTA & I & 16.00 \\
PTA \& Nausea & 2 & 35.50 \\
PTA \& Headache \& Vertigo & I & 13.50 \\
PTA & 5 & 22.50 \\
Decreased LOC \& Nausea & I & 31.00 \\
Confusion & I & 82.50 \\
Headache & 3 & 51.67 \\
Rhinorragia \& Raccoon Eyes & I & 77.00 \\
Amnesia \& Rhinorragia & I & 81.00 \\
Decreased LOC \& Headache & 4 & 63.50 \\
Confusion \& Nausea & I & 71.00 \\
Amnesia \& Nausea & I & 20.00 \\
Amnesia & I & 55.50 \\
Rhinorragia & I & 79.00 \\
Headache \& Agitation & I & 53.00 \\
Nausea \& Agitation & I & 82.50 \\
Total & 86 & 100 \\
\hline
\end{tabular}

Abbreviations: LOC, level of consciousness; PTA, post-traumatic amnesia.

acts better than the serum tau level in detecting CNS damage. ${ }^{19}$ Moreover, taking into account the fact that axonal damage is considered as a basic mechanism for the neurological malfunction after TBI, it is theoretically possible that CTP can be more useful compared to other biomarkers in detecting these injuries. Therefore, the power of CTP biomarker in the diagnosis of PCS and intracranial injury was evaluated in this study. ${ }^{20}$ 
The findings in the present study showed that all patients who were positive for CTP biomarker exhibited TBI. Furthermore, 11 out of 12 cases (91.6\%) of patients with intracranial injury were positive in terms of the CTP biomarkers. This relationship was statistically significant. But Kavalci et al and Guzel et al suggested that serum tau protein has insufficient value in $\mathrm{mTBI} .^{21,22}$ However, Olczak et al show that serum and CSF tau protein may be a marker for diagnosis mTBI. ${ }^{23}$

In a similar study conducted by Bazarian et al, the 6-hr serum levels of cleaved tau and S100B were compared with the 3-month scores of RPCQ questionnaire and PCS. Contrary to the results of this study, it was found that there was no relationship between marker levels and intracranial injury. In addition, in this study, the sensitivity and specificity of CTP were reported as $43 \%$ and $71 \%$, respectively. ${ }^{10}$ However, in the current study, the sensitivity and specificity of this protein in detecting TBI were calculated to be, respectively, 92\% and $100 \%$. In another study by Ma et al, the blood CTP level was measured in 50 patients with mTBI and the results were evaluated using a post-concussive symptom (RPQ) questionnaire and evaluation of acute medical results [Short Form Health Survey (SF-36)] within three months after the trauma. Contrary to the findings of the present study, it was shown that one-third of patients with identifiable c-tau and $14.3 \%$ of the patients without identifiable c-tau had abnormal CT findings; however, this difference was not significant. Furthermore, in this study, the sensitivity and specificity of CTP for the diagnosis of TBI were calculated to be $50 \%$ and $75 \%$, respectively. ${ }^{5}$ Given that the level of GCS, measurement method, and demographic criteria were relatively similar in both studies, the discrepancy is likely to be due to the small sample size in these studies in comparison to the present study. However, due to the very sensitive cutoff level of this marker, interpersonal measurement errors can also affect these differences. Therefore, it seems that high sensitivity methods such as anti-bid flow cytometer or Western blotting should be exploited to remove this difference and achieve a more citable result. Due to the high sensitivity and lower interpersonal changes, these methods can accurately illustrate the relationship between CTP and intracranial injury through eliminating methodological causes.

Besides, while examining the patients, it was revealed that the prevalence of level of consciousness (LOC) symptoms and menorrhagia in patients with intracranial injury was also higher. Although this difference was not statistically significant, it acknowledged the potential of these symptoms in the prediction of intracranial injury. Therefore, the sensitivity and specificity of these symptoms were evaluated for the diagnosis of TBI, and it was found that although these symptoms had a very good specificity in detecting TBI, their sensitivity was very low. Based on the investigations, no studies have yet been conducted to assess the diagnostic power of clinical symptoms in predicting intracranial injury. However, the findings of the present study indicated that it would probably be possible to design a model for the diagnosis of TBI through more accurate assessment of these symptoms and use of other clinical factors.

\section{Limitations}

In the current study, the total tau protein level was not compared with CTP. In addition, the CTP values were expressed only qualitatively based on the cutoff level; these cases were the limitations of the study.

\section{Conclusion}

In general, contrary to previous studies, the findings of this study suggest that evaluation of the CTP levels can be a strong biomarker with high sensitivity and specificity in detecting TBI.

\section{Ethics Statement}

This research was approved by the ethics committee of Welfare Organization, Ahvaz, Iran (IR.AJUMS.REC. 1396.186).

\section{Acknowledgment}

The authors wish to acknowledge the support of the deputy of research affairs of the Ahvaz Jundishapur University of Medical Sciences as part of Sara Zallaghi's thesis under the research code U-96049.

\section{Author Contributions}

All authors contributed to data analysis, drafting and revising the article, gave final approval of the version to be published, and agree to be accountable for all aspects of the work.

\section{Funding}

Ahvaz Jundishapur University of Medical Sciences number: U-96049. 


\section{Disclosure}

The authors declare that they have no conflicts of interest in this work.

\section{References}

1. Langlois JA, Rutland-Brown W, Wald MM. The epidemiology and impact of traumatic brain injury: a brief overview. $J$ Head Trauma Rehabil. 2006;21(5):375-378. doi:10.1097/00001199-200609000-00001

2. Shively SB, Perl DP. Traumatic brain injury, shell shock, and posttraumatic stress disorder in the military-past, present, and future. $J$ Head Trauma Rehabil. 2012;27(3):234-239. doi:10.1097/ HTR.0b013e318250e9dd

3. Kelly JC, Amerson EH, Barth JT. Mild traumatic brain injury: lessons learned from clinical, sports, and combat concussions. Rehabil Res Pract. 2012;2012:371970. doi:10.1155/2012/371970

4. Ma M, Lindsell CJ, Rosenberry CM, Shaw GJ, Zemlan FP. Serum cleaved tau does not predict postconcussion syndrome after mild traumatic brain injury. Am J Emerg Med. 2008;26(7):763-768. doi:10.1016/j.ajem.2007.10.029

5. Bulut M, Koksal O, Dogan S, et al. Tau protein as a serum marker of brain damage in mild traumatic brain injury: preliminary results. $A d v$ Ther. 2006;23(1):12-22. doi:10.1007/BF02850342

6. Chiu WT, Huang SJ, Tsai SH, et al. The impact of time, legislation, and geography on the epidemiology of traumatic brain injury. $J$ Clini Neurosci. 2007;14(10):930-935. doi:10.1016/j.jocn.2006.08.004

7. Johnson VE, Stewart W, Smith DH. Traumatic brain injury and amyloid-beta pathology: a link to Alzheimer's disease? Nature Rev Neurosci. 2010;11(5):361-370. doi:10.1038/nrn2808

8. Li LM, Menon DK, Janowitz T. Cross-sectional analysis of data from the US clinical trials database reveals poor translational clinical trial effort for traumatic brain injury, compared with stroke. PLOS ONE. 2014;9(1):e84336. doi:10.1371/journal.pone.0084336

9. Hyder AA, Wunderlich CA, Puvanachandra P, Gururaj G, Kobusingye OC. The impact of traumatic brain injuries: a global perspective. NeuroRehabilitation. 2007;22(5):341-353.

10. Bazarian JJ, Zemlan FP, Mookerjee S, Stigbrand T. Serum S-100B and cleaved-tau are poor predictors of long-term outcome after mild traumatic brain injury. Brain Inj. 2006;20(7):759-765. doi:10.1080/ 02699050500488207
11. Sharma R, Laskowitz DT. Biomarkers in traumatic brain injury. Curr Neurol Neurosci Rep. 2012;12(5):560-569. doi:10.1007/s11910-0120301-8

12. Bettermann K, Slocomb JE. Clinical relevance of biomarkers for traumatic brain injury. Biomark Traum Brain Inj. 2012;1-18.

13. Sivanandam TM, Thakur MK. Traumatic brain injury: a risk factor for Alzheimer's disease. Neurosci Biobehav Rev. 2012;36 (5):1376-1381. doi:10.1016/j.neubiorev.2012.02.013

14. Blennow K, Hampel H. CSF markers for incipient Alzheimer's disease. Lancet Neurol. 2003;2(10):605-613. doi:10.1016/S14744422(03)00530-1

15. Selkoe DJ, Schenk D. Alzheimer's disease: molecular understanding predicts amyloid-based therapeutics. Annu Rev Pharmacol Toxicol. 2003;43:545-584. doi:10.1146/annurev.pharmtox.43.100901.140248

16. Rubenstein R, Chang B, Davies P, Wagner AK, Robertson CS, Wang KK. A novel, ultrasensitive assay for tau: potential for assessing traumatic brain injury in tissues and biofluids. J Neurotrauma. 2015;32(5):342-352. doi:10.1089/neu.2014.3548

17. Jeter CB, Hergenroeder GW, Hylin MJ, Redell JB, Moore AN, Dash PK. Biomarkers for the diagnosis and prognosis of mild traumatic brain injury/concussion. J Neurotrauma. 2013;30(8):657-670. doi:10.1089/neu.2012.2439

18. Crowther RA, Goedert M. Abnormal tau-containing filaments in neurodegenerative diseases. J Struct Biol. 2000;130(2-3):271-279. doi:10.1006/jsbi.2000.4270

19. Caballero B, Wang Y, Diaz A, et al. Interplay of pathogenic forms of human tau with different autophagic pathways. Aging Cell. 2018;17:1. doi:10.1111/acel.2018.17.issue-1

20. Begaz T, Kyriacou DN, Segal J, Bazarian JJ. Serum biochemical markers for post-concussion syndrome in patients with mild traumatic brain injury. J Neurotrauma. 2006;23(8):1201-1210. doi:10.1089/neu.2006.23.1201

21. Kavalci C, Pekdemir M, Durukan P, et al. The value of serum tau protein for the diagnosis of intracranial injury in minor head trauma. Am J Emerg Med. 2007;25(4):391-395. doi:10.1016/j.ajem.2006.10.008

22. Guzel A, Karasalihoglu S, Aylanc H, Temizoz O, Hicdonmez T. Validity of serum tau protein levels in pediatric patients with minor head trauma. Am J Emerg Med. 2010;28(4):399-403. doi:10.1016/j. ajem.2008.12.025

23. Olczak M, Niderla-Bielinska J, Kwiatkowska M, Samojlowicz D, Tarka S, Wierzba-Bobrowicz T. Tau protein (MAPT) as a possible biochemical marker of traumatic brain injury in postmortem examination. Forensic Sci Int. 2017;280:1-7. doi:10.1016/j.forsciint.2017.09.008
Open Access Emergency Medicine

\section{Publish your work in this journal}

The Open Access Emergency Medicine is an international, peerreviewed, open access journal publishing original research, reports, editorials, reviews and commentaries on all aspects of emergency medicine. The manuscript management system is completely online and includes a very quick and fair peer-review system, which is all easy to use. Visit http://www.dovepress.com/testimonials.php to read real quotes from published authors. 